\title{
Fusarium Head Blight of Cereals in Denmark: Species Complex and Related Mycotoxins
}

\author{
L. K. Nielsen, J. D. Jensen, G. C. Nielsen, J. E. Jensen, N. H. Spliid, I. K. Thomsen, \\ A. F. Justesen, D. B. Collinge, and L. N. Jørgensen
}

First, fifth, seventh, and ninth authors: Aarhus University, Faculty of Agricultural Science, Department of Integrated Pest Management, Research Centre Flakkebjerg, Denmark; second and eighth authors: University of Copenhagen, Faculty of Life Sciences, Department of Plant Biology and Biotechnology, Frederiksberg, Denmark; third and fourth authors: Knowledge Centre for Agriculture, Crop Production, Aarhus, Denmark; and sixth author: Aarhus University, Faculty of Agricultural Science, Department of Agroecology and Environment, Research Centre Foulum, Denmark.

Accepted for publication 31 January 2011.

\section{ABSTRACT}

Nielsen, L. K., Jensen, J. D., Nielsen, G. C., Jensen, J. E., Spliid, N. H., Thomsen, I. K., Justesen, A. F., Collinge, D. B., and Jørgensen, L. N. 2011. Fusarium head blight of cereals in Denmark: Species complex and related mycotoxins. Phytopathology 101:960-969.

Quantitative real-time polymerase chain reaction differentiating 10 Fusarium spp. and Microdochium nivale or M. majus was applied to a total of 396 grain samples of wheat, barley, triticale, oat, and rye sampled across Denmark from 2003 to 2007, along with selected samples of wheat and barley from 1957 to 2000, to determine incidence and abundance of individual Fusarium spp. The mycotoxins deoxynivalenol (DON), nivalenol, zearalenone, T-2, and HT-2 were quantified using liquid chromatography-double mass spectrometry. Major differences in the
Fusarium species complex among the five cereals as well as great yearly variation were seen. Fusarium graminearum, $F$. culmorum, and $F$. avenaceum were dominant in wheat, with DON as the dominant mycotoxin. $F$. langsethiae, F. culmorum, and $F$. avenaceum were dominant in barley and oat, leading to relatively high levels of the mycotoxins T-2 and HT-2. $F$. graminearum, $F$. culmorum, and $F$. avenaceum dominated in triticale and rye. The nontoxigenic $M$. nivale/majus were present in significant amounts in all cereal species. Wheat and barley samples from 1957 to 1996 exhibited no or very low amounts of $F$. graminearum, indicating a recent increase of this pathogen. Biomass and mycotoxin data exhibited good correlations between Fusarium spp. and their corresponding mycotoxins under field conditions.
Fusarium head blight (FHB) in small grain cereals is caused by a complex of toxigenic pathogens belonging to the genus $\mathrm{Fu}$ sarium (Gibberella) and the nontoxigenic genus Microdochium. The result of FHB worldwide is lower grain yield and reduced quality due to mycotoxins. The most common Fusarium spp. in this complex found throughout Europe are Fusarium graminearum (Gibberella zeae), $F$. avenaceum ( $G$. avenacea), and $F$. culmorum (5). However, $F$. poae, $F$. tricinctum, $F$. sporotrichioides, $F$. equiseti, and $F$. langsethiae are also frequently found $(5,21,44)$. The distribution of the pathogens causing FHB is believed to be determined, in part, by climatic factors such as temperature and moisture (41). F. graminearum has traditionally been found to dominate in regions with warm and humid growth conditions; $F$. avenaceum and $F$. culmorum are both associated with cool, wet, and humid conditions; and Microdochium nivale and M. majus are associated with regions of relatively cool temperatures and frequent short rain showers (42).

In addition to climatic factors, agronomic factors are also very important for the occurrence of FHB. Soil tillage and previous crops have been shown to have a significant influence on FHB or mycotoxin contamination $(7,10,27)$. The Fusarium spp. produce several mycotoxins which pose a health risk to humans and animals through food and feed prepared from contaminated crops (11). The mycotoxins produced by the Fusarium spp. include the

Corresponding author: L. N. Jørgensen; E-mail address: lnj@agrsci.dk

* The $\boldsymbol{e}$-Xtra logo stands for "electronic extra" and indicates that Figures 1, 2, and 3 appear in color online.

doi:10.1094/PHYTO-07-10-0188

(c) 2011 The American Phytopathological Society trichothecenes, zearalenone (ZEA), moniliformin, fumonisins, and the enniatins. Trichothecenes constitute the largest group of mycotoxins produced by Fusarium spp. in cereal grain; these can be divided into two groups: type A and type B (24). The type B trichothecenes are the most common trichothecenes and include deoxynivalenol (DON) and the closely related nivalenol (NIV). DON is produced by $F$. graminearum and $F$. culmorum, and NIV is produced by some isolates of these two species as well as by $F$. poae and $F$. equiseti (24). F. graminearum and $F$. culmorum are also producers of ZEA, which occurs commonly along with DON and similar derivates (5). Type A trichothecenes includes T-2 mycotoxin, HT-2 mycotoxin, and diacetoxyscirpenol (DAS) and are considered to be more toxic to humans and animals than type B trichothecenes (22). The mycotoxins T-2 and HT-2 are produced primarily by $F$. langsethiae and $F$. sporotrichioides; also, a few isolates of $F$. poae have been reported as HT-2 and T-2 producers (35). DAS is produced by $F$. poae and $F$. equiseti, whereas $F$. avenaceum and $F$. tricinctum produce, among other metabolites, the mycotoxins monilformin, beauvericin, and enniatins (35).

Due to differences in pathogenicity, toxigenicity, and fungicide sensitivity, it is important to obtain detailed knowledge of the occurrence of individual Fusarium spp., and a prerequisite for this is the correct identification and quantification of individual species. However, the classical morphological methods for identification of Fusarium spp. in grain samples are both laborious and require a high level of expertise in order to distinguish closely related species, and will only provide information on incidence of the pathogen infection in seed. In contrast to conventional tests, polymerase chain reaction (PCR)-based methods have the advantage of species specificity, sensitivity, and speed. Furthermore, 
quantitative (Q)PCR offers the opportunity for quantifying fungal biomass. Several QPCR assays have been developed for identification and quantification of individual Fusarium spp. (26), and QPCR methods have been developed which facilitate the detection and quantification of individual Fusarium spp. in cereals $(25,37)$. Glynn and Edwards (12) compared QPCR assays to the traditional morphological approach and concluded that the amount of pathogen DNA provides a useful estimate of seed batch contamination for Microdochium but not for Fusarium pathogens, where large levels of variations were detected between the two methods. The variations can be explained by the fact that PCRbased methods detect all fungal DNA of interest without distinguishing live or dead cells and species competition, whereas morphological identification requires live organisms that are easily cultivable. Each kernel is colonized by a mixture of different fungal species, not all of them belonging to the FHB complex. There will be a competition between these different species in in vitro culture, and single species might outgrow the others (38). The morphological identification provides another difficulty in accurate incidence estimation because surfacesterilization of seed will destroy inoculum on the seed surface (29). Furthermore, PCR methods allow detection of degenerate and otherwise difficult cultures such as $F$. langsethiae, which is difficult to isolate from grain samples (44).

The perception as to which Fusarium spp. are responsible for FHB in Denmark has been based on survey studies performed in other European countries and from classical morphological studies of limited selected grain samples from Danish barley $(1,33,39)$. The use of a QPCR method which is based on detection of the same gene, the translation elongation factor $1 \alpha$ gene (TEF$1 \alpha$ ), in all Fusarium spp. makes it possible to obtain detailed information on the occurrence of Fusarium spp. in cereal grain. The present study represents the first comprehensive monitoring of its kind in Denmark and, indeed, is the first study where QPCR methodology targeting the same single gene in all the investigated species has been applied to a large number of samples covering a broad span of time originating from several cereal species anywhere. The samples of this study originate from a monitoring project established in 2003 by the Danish Knowledge Centre For Agriculture, Crop Production in order to study the extent of the problem of Fusarium mycotoxins in cereals and to study the effect of farming practices such as tilling and crop rotation on the mycotoxin production. The aim of the present study was to investigate the composition of the FHB species complex as well as to determine associations between the occurrence of Fusarium spp. and their mycotoxins in cereal samples in five seasons. In addition, a set of pooled grain samples representing the years 1957 to 2000 was investigated in order to obtain knowledge of the general composition of the FHB complex prior to 2003.

\section{MATERIALS AND METHODS}

Field samples. Fields samples of cereal grain were collected in 2003 to 2007 and consisted of harvested seed from fields evenly distributed throughout Denmark as part of a stratified monitoring program for mycotoxins in Danish cereal crops. A sample of $100 \mathrm{~g}$ was taken out of an original 1-kg grain sample harvested from farmers' fields. In total, 227 wheat samples from 2003 to 2007 (41 to 50 samples each year) were selected along with 61 barley and 53 triticale grain samples from 2005 to 2007 ( $\approx 20$ samples per year) and 22 oat and 17 rye grain samples from 2007. In general, the samples represent the broad variation in Danish farming practice with respect to cultivar, soil, fertilization, and fungicide treatment (G. C. Nielsen, unpublished data). However, there is an overrepresentation of wheat samples with wheat as previous crop as well as reduced tillage (23\%) compared with a total area of $3 \%$ with these conditions in Denmark. After harvest, the grain samples were dried to a water content of 15 to $16 \%$, mycotoxin analyses were performed, and the samples were stored at $-20^{\circ} \mathrm{C}$ before DNA extraction.

Historical samples. Milled grain samples of winter wheat and spring barley were obtained from the ASKOV long-term studies of animal manure and mineral fertilizers situated in Mid-Jutland. The ASKOV long-term studies began in 1894 (9) and the samples used for this survey were obtained during 1957 to 2000. Each sample was provided as a pooled sample consisting of pooled subsamples from 4 years based on four to five replicates pooled from each year. The samples originate from field plots fertilized according to common practice (9) and stored as milled grain in closed containers at room temperature.

Fungal isolates. The Fusarium isolates used for standard curves and positive controls were obtained from the IBT culture collection at the Technical University of Denmark: F. graminearum 1955, F. culmorum 9560, $F$. avenaceum 8500, $F$. tricinctum $8048, F$. poae $8452, F$. langsethiae $8150, F$. sporotrichioides 1926, F. equiseti 8752, F. verticilloides 8002, F. proliferatum $\mathrm{B} 8376 \mathrm{~B}$.

DNA extraction. Prior to DNA extraction, the fungal isolates were grown on potato dextrose agar (PDA) at $22^{\circ} \mathrm{C}$ under $12 \mathrm{~h}$ of light and $12 \mathrm{~h}$ of darkness. Mycelium was scraped off the agar using a spatula and ground in liquid $\mathrm{N}_{2}$ with eight steel balls using a Geno/Grinder 2000 (OPS Diagnostics, Bridgewater, NJ). Ground mycelium (100 mg) was used for DNA extraction, using the cetyltrimethylammonium bromide method according to Nicolaisen et al. (25). The concentration of DNA from the fungal isolates used for standard curves was determined using NanoDrop 1000 (Thermo Fisher Scientific, MA). The same method was used for extraction of DNA from grain samples using $100 \mathrm{mg}$ of powdered grain material.

Primers for real-time PCR. Primers designed by Nicolaisen et al. (25) were used for this study. These primers are based on the TEF-1 $\alpha$ in fungal and plant genomes. Primers for the following 10 different species were used: F. graminearum, F. culmorum/F. cerealis, $F$. avenaceum, $F$. tricinctum, $F$. poae, $F$. langsethiae, $F$. sporotrichioides, F. equiseti, $F$. verticilloides, and $F$. proliferatum. A specific primer pair identifying $M$. nivale and $M$. majus as one, and distinguishing this genus from Fusarium, was designed based on the TEF- $1 \alpha$ gene sequences of both species (13) using the Primer Express program (version 2.0; Applied Biosystems, Foster City, CA). The primers were Mniv283F: 5'-CCAAGCA GGTCGCTTTCGT-3' and Mniv333R: 5'-GCATGTTGTCGCG TTGA-3'. The specificity of the primers were tested on four isolates of M. majus (B-M, B-C, and REF from Scotland, kindly provided by V. Cockerell, Scottish Agricultural Science Agency; and CBS 106.90) and one isolate of M. nivale (CBS 162.7) together with reference isolates of $F$. graminearum, $F$. culmorum, $F$. avenaceum, $F$. tricinctum, $F$. poae, $F$. langsethiae, $F$. sporotrichioides, $F$. equiseti, $F$. verticilloides, and $F$. proliferatum and cereal DNA as described by Nicolaisen et al. (25).

Quantification of Fusarium DNA. Real-time PCR was carried out in a total of $12.5 \mu$ l consisting of $6.25 \mu \mathrm{l}$ of $2 \times$ SYBR Green PCR Master Mix (Applied Biosystems), $250 \mathrm{nM}$ each primer, bovine serum albumin at $0.5 \mu / \mu \mathrm{l}$, and $2.5 \mu \mathrm{l}$ of template DNA. PCR reactions were performed in duplicate on all samples. Genomic DNA from grain samples and pure cultures was diluted 1:10 before PCR. PCR was performed on a 7900HT Sequence Detection System (Applied Biosystems) using the following cycling protocol: $2 \mathrm{~min}$ at $50^{\circ} \mathrm{C} ; 95^{\circ} \mathrm{C}$ for $10 \mathrm{~min} ; 40$ cycles of $95^{\circ} \mathrm{C}$ for $15 \mathrm{~s}$ and $62^{\circ} \mathrm{C}$ for $1 \mathrm{~min}$; followed by dissociation analysis at 60 to $95^{\circ} \mathrm{C}$. For the plant assay, annealing and extension were performed at $60^{\circ} \mathrm{C}$. The field samples were analyzed using the 11 specific assays. A standard curve was produced for the plant assay based on a field sample with known DNA concentration determined using NanoDrop 1000 (Thermo Scientific, Wilmington, DE). Individual standard curves were made of fivefold dilution series using pure fungal DNA and plant DNA. 
Amplification efficiency of the plant assay was investigated on fivefold serial dilution $(6,000$ to $10 \mathrm{pg})$ of DNA extracted from samples of wheat, barley, triticale, rye, and oat in T0.1E $(10 \mathrm{mM}$ Tris- $\mathrm{HCl}, \mathrm{pH} 8.0$, and $0.1 \mathrm{mM}$ EDTA). The amount of fungal DNA was calculated from the cycle threshold $(\mathrm{Ct})$ values using the standard curve. Because SYBR Green binds to all doublestranded DNA, the results of each individual sample from each species-specific assay were evaluated by studying the dissociation curve and $\mathrm{Ct}$ value. The plant assay was used to determine the DNA yield and to ensure that no degradation had taken place during storage of the samples. The plant assay was further used to provide a normalized measurement for biomass in each sample, which was calculated as picograms of fungal DNA per micrograms of plant DNA according to Nicolaisen et al. (25). Amplification efficiency and cross reaction of species with nearly identical TEF- $1 \alpha$ genes were investigated by making fivefold serial dilutions of pure DNA of F. langsethiae (360 to $0.6 \mathrm{pg}$ ) in a constant background of pure DNA $F$. sporotrichioides $(300 \mathrm{pg}$ ) as well as in T0.1E, respectively, using $F$. langsethiae-specific primers. The same investigations were made on fivefold serial dilutions of pure DNA of $F$. graminearum (150 to $0.24 \mathrm{pg}$ ) in a constant background of pure DNA of F. culmorum (500 pg) and in T0.1E using $F$. graminearum-specific primers. The efficiency $[E=$ $\left.10^{(-1 / \text { slope })}-1\right]$ was calculated from the slope of the linear relationship of the $\log _{10}$ values of the DNA concentration and the cycle number $(\mathrm{Ct})$.

Analysis of mycotoxins. Grain samples were analyzed for Fusarium mycotoxins DON, NIV, ZEA, HT-2, and T-2 by liquid chromatography-double mass spectrometry (LC-MS/MS) according to Nicolaisen et al. (25). The detection limits of the mycotoxins were $10 \mu \mathrm{g} \mathrm{kg}^{-1}$ for DON, NIV, and HT-2; $2 \mu \mathrm{g} \mathrm{kg}^{-1}$ for $\mathrm{ZEA}$; and $5 \mu \mathrm{g} \mathrm{kg} \mathrm{g}^{-1}$ for T2.

Statistical analysis. Correlation analyses were performed for levels of mycotoxins (DON, NIV, ZEA, HT2, and T2) and biomass of $F$. graminearum, $F$. culmorum, $F$. avenaceum, $F$. tricinctum, $F$. poae, $F$. sporotrichioides, $F$. langsethiae, and $M$. nivale/majus (i.e., 13 variables in total). Samples with mycotoxin or fungal biomass levels below the detection limits were set to 5 and 2 , respectively, in order to facilitate $\log$ transformation of data. Replacing 0 for mycotoxin determination with 5 reflects the approximate detection limit for the five individual mycotoxins analyzed. Biomass amounts of 0 were replaced with the arbitrary value 2 , which will not give a large deviation when log transformed. All data were subsequently log transformed to stabilize variances, and exploratory principal component analysis (PCA) on the correlation matrix of the variables was performed using the statistical program Paleontological Statistics (PAST) (14). The PCAs decompose the correlated variables into underlying uncorrelated latent structures (principal components) capturing the highest degree of the total variation across all variables in as low a dimension as possible. PCA is a bilinear model that produces a scores matrix $(\mathrm{n}, \mathrm{k})$ and a loading matrix $(\mathrm{p}, \mathrm{k})$, also sometimes referred to as the left and right eigenvectors, respectively; "n" represents the number of samples, " $p$ " the number of variables, and " $k$ " the number of principal components. The score matrix shows how the different samples are distributed with respect to the main variation described in the first $\mathrm{k}$ components. The loading matrix shows why (i.e., which variables span the variation in the different components). PCA can be used as an explorative tool to reveal associations among variables, and allows interpretations that would not otherwise be apparent (19). Furthermore, PCA splits data into a systemic part, captured by the first and most significant principal components, and an unsystematic part, captured in a residual matrix. Consequently, the underlying significance of the principal components is less uncertain than for the original variables where compared directly. The results of the PCA were interpreted graphically by drawing biplots, where scatter plot of the score matrix as point and the loading matrix as arrows for the first two components are superimposed for a condensed representation of the correlation between the original variables (Fusarium spp. and mycotoxins) and the distribution of the samples.

\section{RESULTS}

Reproducibility and validation of assays. Quantification of DNA of the five different cereal species showed a linear relationship between $\log _{10}$ values of the amount of genomic DNA and Ct values, with $R^{2}$ values of 0.989 to 0.993 and $E$ values of 91 to $100 \%$, where barley and oat generally had the lowest $E$ values and rye and wheat the highest.

The specificity of the species-specific assays has previously been verified in Nicolaisen et al. (25) on DNA from pure fungal isolates. In the present study, the influence of closely related species with almost identical TEF- $1 \alpha$ genes was investigated by making serial dilutions of $F$. langsethiae DNA in a constant background of $F$. sporotrichioides DNA $\left(E=110 \%, R^{2}=0.989\right)$ and serial dilutions of $F$. langsethiae in T0.1E $\left(E=91 \%, R^{2}=\right.$ $0.991)$ using $F$. langsethiae-specific primers. The same test was performed for serial dilutions of $F$. graminearum DNA in a constant background of $F$. culmorum DNA $\left(E=105 \%, R^{2}=\right.$ $0.987)$ and $F$. graminearum in T0.1E $\left(E=93 \%, R^{2}=0,992\right)$ using $F$. graminearum-specific primers. In both tests, the efficiency of the assays increased when a high constant background of competitive DNA was present, which may lead to overestimation of either $F$. langsethiae or $F$. graminearum in very high backgrounds of closely related species. The amounts of $F$. sporotrichioides and F. culmorum DNA used in the experiments were higher than detected in any field samples.

Incidences of Fusarium spp. in Danish cereals. Speciesspecific QPCR assays were used to quantify incidence and biomass (DNA) of Fusarium spp. and Microdochium spp. in 379 grain samples from 2003 to 2007 . The frequency in which eight Fusarium spp. and M. nivale/majus were found in wheat, barley, triticale, oat, and rye is described in Table 1 . The most frequent species in wheat through the period of study (2003 to 2007) were $F$. avenaceum, $F$. graminearum, and $F$. culmorum, which were all found in $>80 \%$ of the samples. Lower incidences of $F$. poae, $F$. langsethiae, and $F$. tricinctum were recorded; the frequency varied between 60 and $70 \%$ of the samples. F. sporotrichioides occurred very rarely, in $<11 \%$ of the samples, and $F$. equiset $i$ was found only in a single wheat sample. In barley, the most frequent species in the period 2005 to 2007 were $F$. poae, F. culmorum, $F$. avenaceum, $F$. langsethiae, and $F$. graminearum, which were found, on average, in $>85 \%$ of the samples. F. tricinctum was found in $67 \%$ of the samples, $F$. sporotrichioides in $15 \%$, and $F$. equiseti in $2 \%$. In triticale, the most frequent species in the period 2005 to 2007 were $F$. poae and $F$. culmorum, which were found in $>74 \%$ of the samples. F. avenaceum and $F$. graminearum were found in $\approx 50 \%$ of the triticale samples, whereas $F$. langsethiae and F. tricinctum were found in $<20 \%$ of the samples and $F$. sporotrichioides and $F$. equiseti were not found at all. In oat, $F$. avenaceum was the most frequent species in 2007, with an incidence of $100 \%$, followed by $F$. poae and $F$. langsethiae, both exhibiting an incidence of $86 \%$, and $F$. graminearum and $F$. culmorum, with $82 \%$. F. tricinctum and F. sporotrichioides were less frequent, with 55 and $27 \%$, respectively. In rye, the most frequent species in 2007 were $F$. avenaceum and $F$. culmorum, both with an incidence of $94 \%$, followed by $F$. poae and $F$. graminearum, with an incidence of 88 and $71 \%$, respectively. $F$. langsethiae was found in $18 \%$ of the rye samples and F. sporotrichioides and $F$. tricinctum were found at an even lower frequency, with $6 \%$ incidence for both. No F. equiseti was found in rye. $F$. proliferatum and $F$. verticilloides were not found in any of the cereal samples. The nontoxigenic $M$. nivale/majus was, on average, found in $>90 \%$ of the samples across years and cereal species. 
Fusarium and $M$. nivale/majus biomass and mycotoxin. The biomass of Fusarium spp. and M. nivale/majus (DNA) and the amount of Fusarium mycotoxins found in Danish cereal grain samples from 2003 through 2007 are shown in Tables 2 to 5. For each species, there is a large variation between years but also large variability between the samples within each year, and this is reflected in the $95 \%$ confidence interval. The nontoxigenic $M$. nivale/majus generally occurred at a higher biomass than most of the Fusarium spp. in all years across the cereal species, with the exception of $F$. graminearum in wheat. Compared with the other cereal species, the amounts of $M$. nivale/majus in wheat were generally lower.
It is clear that a relatively larger biomass was present for $F$. graminearum than for any other Fusarium spp. throughout the study (Table 2). Relatively lower amounts of $F$. avenaceum, $F$. langsethiae, and $F$. culmorum and even lower amounts of $F$. poae and $F$. tricinctum were observed; finally, only traces of $F$. sporotrichioides were found. F. graminearum exhibited $\leq 10$-fold differences in biomass between the years 2003 and 2004, where high amounts of this species were found, compared with 2006, where low levels were recorded. Relatively high levels of $F$. avenaceum were seen in 2003 and 2004. The type B trichothecenes (DON and NIV) were the most prevalent mycotoxins during the years. Especially in 2003 and 2004, the amounts of DON were

TABLE 1. Incidences of Fusarium spp. and Microdochium nivale/majus in wheat (2003 to 2007), barley (2005 to 2007), triticale (2005 to 2007), oat (2007), and rye (2007) and across years for wheat, barley, and triticale, given as percentages ${ }^{\mathrm{a}}$

\begin{tabular}{|c|c|c|c|c|c|c|c|c|c|c|c|c|c|c|c|c|}
\hline \multirow[b]{2}{*}{ Species } & \multicolumn{5}{|c|}{ Wheat } & \multicolumn{3}{|c|}{ Barley } & \multicolumn{3}{|c|}{ Triticale } & \multirow{2}{*}{$\frac{\text { Oat }}{2007}$} & \multirow{2}{*}{$\begin{array}{l}\text { Rye } \\
2007\end{array}$} & \multirow{2}{*}{$\frac{\text { Wheat }}{\text { All }}$} & \multirow{2}{*}{$\frac{\text { Barley }}{\text { All }}$} & \multirow{2}{*}{$\frac{\text { Triticale }}{\text { All }}$} \\
\hline & 2003 & 2004 & 2005 & 2006 & 2007 & 2005 & 2006 & 2007 & 2005 & 2006 & 2007 & & & & & \\
\hline $\mathrm{Fg}$ & 100 & 100 & 83 & 67 & 86 & 75 & 85 & 100 & 78 & 53 & 44 & 82 & 71 & 87 & 87 & 58 \\
\hline$F c$ & 83 & 91 & 72 & 60 & 96 & 85 & 100 & 90 & 67 & 71 & 83 & 82 & 94 & 86 & 92 & 74 \\
\hline$F t$ & 63 & 41 & 51 & 53 & 88 & 55 & 70 & 81 & 0 & 6 & 11 & 55 & 6 & 60 & 67 & 6 \\
\hline$F p$ & 88 & 75 & 60 & 60 & 70 & 100 & 100 & 100 & 72 & 82 & 94 & 86 & 88 & 70 & 100 & 83 \\
\hline Fs & 17 & 32 & 4 & 2 & 2 & 10 & 20 & 14 & 0 & 0 & 0 & 27 & 6 & 11 & 15 & 0 \\
\hline$M$ & 98 & 100 & 94 & 60 & 100 & 100 & 100 & 100 & 100 & 94 & 100 & 100 & 100 & 90 & 100 & 98 \\
\hline
\end{tabular}

a Abbreviations: $F$. graminearum $(F g), F$ culmorum $(F c), F$. avenaceum $(F a), F$. tricinctum $(F t), F$. poae $(F p), F$. sporotrichioides $(F s), F$. langsethiae $(F l), M$. nivale/majus (M). Wheat: 2003, $n=41 ; 2004, n=44 ; 2005, n=47 ; 2006, n=45 ; 2007, n=50 ;$ total $n=227$. Barley: 2005, $n=20 ; 2006, n=20 ; 2007, n=21$; total $n=61$. Triticale: $2005, n=18 ; 2006, n=17 ; 2007, n=18$; total $n=53$. Oat: $n=22$. Rye: $n=17$. All = all years.

TABLE 2. Amounts of Fusarium spp., Microdochium nivale/majus, and the mycotoxins deoxynivalenol (DON), nivalenol (NIV), zearalenone (ZEA), HT-2, and T-2 in wheat grain samples collected in Danish fields in 2003 to 2007 described by mean values and $95 \%$ confidence interval $^{\mathrm{a}}$

\begin{tabular}{|c|c|c|c|c|c|c|c|c|c|c|c|c|c|c|}
\hline \multirow[b]{2}{*}{ Year } & \multirow[b]{2}{*}{$n$} & \multicolumn{8}{|c|}{ Amount of Fusarium DNA (pg of fungal DNA/ $\mu \mathrm{g}$ of plant DNA) } & \multicolumn{5}{|c|}{ Fusarium mycotoxins $\left(\mu \mathrm{g} \mathrm{kg}^{-1}\right)$} \\
\hline & & $F g$ & $F c$ & $F a$ & Ft & $F p$ & Fs & $\mathrm{Fl}$ & $M$ & DON & NIV & ZEA & HT-2 & $\mathrm{T}-2$ \\
\hline 2003 & 41 & $1,480 \pm 356$ & $342 \pm 106$ & $638 \pm 184$ & $178 \pm 96$ & $143 \pm 39$ & $10 \pm 8$ & $570 \pm 201$ & $579 \pm 173$ & $562 \pm 188$ & $28 \pm 8$ & $1 \pm 1$ & $1 \pm 2$ & 0 \\
\hline 2004 & 44 & $8,359 \pm 7,433$ & $305 \pm 98$ & $815 \pm 337$ & $81 \pm 70$ & $81 \pm 34$ & $16 \pm 8$ & $92 \pm 92$ & $750 \pm 252$ & $916 \pm 723$ & $19 \pm 7$ & $99 \pm 79$ & $3 \pm 3$ & $1 \pm 1$ \\
\hline 2006 & 45 & $1,067 \pm 850$ & $67 \pm 34$ & $82 \pm 43$ & $43 \pm 23$ & $128 \pm 51$ & 0 & $213 \pm 61$ & $45 \pm 18$ & $153 \pm 61$ & $8 \pm 5$ & $25 \pm 22$ & $3 \pm 2$ & $1 \pm 1$ \\
\hline 2007 & 50 & $1,334 \pm 1,238$ & $224 \pm 80$ & $234 \pm 87$ & $93 \pm 57$ & $141 \pm 75$ & $9 \pm 17$ & $99 \pm 51$ & $959 \pm 183$ & $327 \pm 228$ & $16 \pm 8$ & $18 \pm 20$ & $2 \pm 2$ & $0.3 \pm 0.6$ \\
\hline
\end{tabular}

a Abbreviations: F. graminearum $(F g), F$. culmorum $(F c), F$. avenaceum $(F a), F$. tricinctum $(F t), F$. poae $(F p), F$. sporotrichioides $(F s), F$. langsethiae $(F l)$, M. nivale/majus $(M) ; n=$ number of tested samples; $95 \%=95 \%$ of the samples are found in this interval. Detection limits: DON, NIV, and $\mathrm{HT}^{-2}>10 \mu \mathrm{kg} \mathrm{kg}^{-1}$; $\mathrm{ZEA}>2 \mu \mathrm{g} \mathrm{kg}{ }^{-1} ; \mathrm{T}-2>5 \mu \mathrm{g} \mathrm{kg}-1$.

TABLE 3. Amounts of Fusarium spp., Microdochium nivale/majus, and the mycotoxins deoxynivalenol (DON), nivalenol (NIV), zearalenone (ZEA), HT-2, and T-2 in barley grain samples collected in Danish fields in 2003 to 2005 described by mean values and $95 \%$ confidence interval $^{\mathrm{a}}$

\begin{tabular}{|c|c|c|c|c|c|c|c|c|c|c|c|c|c|c|}
\hline \multirow[b]{2}{*}{ Year } & \multirow[b]{2}{*}{$n$} & \multicolumn{8}{|c|}{ Amount of Fusarium DNA (pg fungal DNA/ $\mu \mathrm{g}$ of plant DNA) } & \multicolumn{5}{|c|}{ Fusarium mycotoxins $\left(\mu \mathrm{g} \mathrm{kg}^{-1}\right)$} \\
\hline & & $\mathrm{Fg}$ & $F c$ & $\mathrm{Fa}$ & Ft & $F p$ & Fs & $\mathrm{Fl}$ & $M$ & DON & NIV & ZEA & HT-2 & $\mathrm{T}-2$ \\
\hline 05 & 20 & $114 \pm$ & & & & & $8 \pm 12$ & & & & 2 & 0 & 0 & 0 \\
\hline 2006 & 20 & $57 \pm 51$ & $1,645 \pm, 2677$ & $923 \pm 1,548$ & $565 \pm 365$ & $987 \pm 779$ & $36 \pm 39$ & $4,197 \pm 2,230$ & $542 \pm 388$ & $19 \pm 13$ & $21 \pm 13$ & 0 & $20 \pm 9$ & $5 \pm 3$ \\
\hline
\end{tabular}

a Abbreviations: F. graminearum $(F g), F$. culmorum $(F c), F$. avenaceum $(F a), F$. tricinctum $(F t), F$. poae $(F p), F$. sporotrichioides $(F s), F$. langsethiae $(F l)$, M. nivale/majus $(M) ; n=$ number of samples tested; $95 \%=95 \%$ of the samples are found in this interval. Detection limits: DON, NIV, and HT-2 $>10 \mu \mathrm{kg} \mathrm{k}^{-1}$; $\mathrm{ZEA}>2 \mu \mathrm{g} \mathrm{kg}{ }^{-1} ; \mathrm{T}-2>5 \mu \mathrm{g} \mathrm{kg}{ }^{-1}$.

TABLE 4. Amounts of Fusarium spp., Microdochium nivale/majus, and the mycotoxins deoxynivalenol (DON), nivalenol (NIV), zearalenone (ZEA), HT-2, and T-2 $\left(\mu \mathrm{g} \mathrm{kg}^{-1}\right)$ in triticale grain samples collected in Danish fields in 2003 to 2005 described by mean values and $95 \%$ confidence interval $^{\mathrm{a}}$

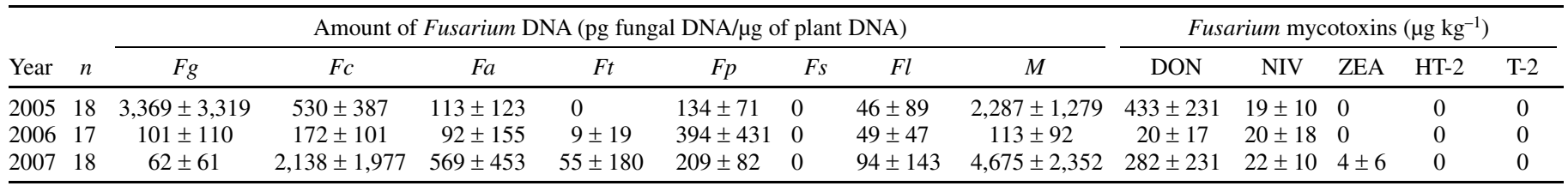

${ }^{a}$ Abbreviations: F. graminearum $(F g), F$. culmorum $(F c), F$. avenaceum $(F a), F$. tricinctum $(F t), F$. poae $(F p), F$ sporotrichioides $(F s), F$ langsethiae $(F l)$, M. nivale/majus $(M) ; n=$ number of tested samples; $95 \%=95 \%$ of the samples are found in this interval. Detection limits: DON, NIV, and HT-2 $>10 \mu \mathrm{g} \mathrm{kg}{ }^{-1}$; ZEA $>2 \mu \mathrm{g} \mathrm{kg}{ }^{-1} ; \mathrm{T}-2>5 \mu \mathrm{g} \mathrm{kg}{ }^{-1}$. 
higher compared with the amounts found in other years. In 2005, no ZEA, HT-2, or T-2 was detected and, apart from 2004, the amount of ZEA was found to be low in all years. The levels of type A trichothecenes HT-2 and T-2 were generally low.

For barley (Table 3), F. langsethiae was generally the predominant Fusarium sp. in terms of biomass across the years. However, the biomass of $M$. nivale/majus was higher. This was followed by $F$. culmorum, $F$. avenaceum, $F$. tricinctum, and $F$. poae, which again exhibited higher amounts of DNA than $F$. graminearum, whereas $F$. sporotrichioides was less abundant. There were large variations in biomasses between years (e.g., $F$. langsethiae showed a difference of sixfold between years, whereas it was fairly stable for others, such as F. tricinctum, which differed less than twofold across the years). The Fusarium mycotoxins present were found to reflect the presence of both type Aand type B-producing species, with generally low amounts of both types and very low amounts of ZEA.

$F$. graminearum and $F$. culmorum were the species with the highest biomass in triticale across years (Table 4). These were followed by $F$. avenaceum and $F$. poae, which both had biomass at relatively higher levels than $F$. langsethiae and F. tricinctum. F. sporotrichioides was not found in any of the samples. There was large variation in biomass of the individual species between years (e.g., F. graminearum and F. culmorum) Thus, in 2005, the biomass of $F$. graminearum was 6-fold higher than that of $F$. culmorum but, in 2006, the biomass of both was relatively low and, in 2007, the biomass of F. culmorum was 34-fold higher than for $F$. graminearum. The Fusarium mycotoxins present were found to reflect the presence of mainly type B-producing species. In 2005 and 2007, the biomass of either $F$. graminearum or $F$. culmorum was relatively high, which was consistent with the high levels of DON observed. Low levels of NIV were found in all years, ZEA was only found at very low levels in 2007, and no HT2 and $\mathrm{T}-2$ was detected.

$F$. langsethiae and $F$. avenaceum were the dominant species in oat samples (Table 5). These species were followed by F. graminearum, $F$. poae, $F$. tricinctum, and $F$. culmorum, all of which were present at higher levels than $F$. sporotrichioides. In rye, the species showing the highest amount of biomass were $F$. avenaceum and $F$. culmorum. These were followed by $F$. graminearum and $F$. poae, which had relatively larger biomass than $F$. langsethiae, F. tricinctum, and F. sporotrichioides. The Fusarium mycotoxins found in oat reflected the presence of both type Aand type B-producing species whereas mainly type B-producing species were found primarily in rye. Low levels of ZEA were found in both oat and rye.

The occurrence of Fusarium spp. and M. nivale/majus in wheat and barley is described in Tables 6 and 7, respectively, for 1957 to 2000. F. culmorum and F. poae were found in all years in both wheat and barley. Low levels of $F$. graminearum were found in

TABLE 5. Amounts of Fusarium spp., Microdochium nivale/majus, and the mycotoxins deoxynivalenol (DON), nivalenol (NIV), zearalenone (ZEA), HT-2, and T2 in oat and rye grain samples collected in Danish fields in 2007 described by mean values and $95 \%$ confidence interval ${ }^{\mathrm{a}}$

\begin{tabular}{|c|c|c|c|c|c|c|c|c|c|c|c|c|c|c|}
\hline \multirow[b]{2}{*}{ Cereal } & \multirow[b]{2}{*}{$n$} & \multicolumn{8}{|c|}{ Amount of Fusarium DNA (pg fungal DNA/ $\mu \mathrm{g}$ of plant DNA) } & \multicolumn{5}{|c|}{ Fusarium mycotoxins $\left(\mu \mathrm{g} \mathrm{kg}^{-1}\right)$} \\
\hline & & $\mathrm{Fg}$ & $F c$ & $F a$ & $F t$ & $F p$ & Fs & $F l$ & $M$ & DON & NIV & ZEA & HT-2 & $\mathrm{T}-2$ \\
\hline Oat & 22 & $1,409 \pm 2,548$ & $646 \pm 270$ & $2,467 \pm 926$ & $692 \pm 335$ & $903 \pm 500$ & $57 \pm 83$ & $2,595 \pm 1,028$ & $8,955 \pm 3,741$ & $44 \pm 25$ & $45 \pm 30$ & $1 \pm 1$ & $57 \pm 26$ & $19 \pm 21$ \\
\hline Rye & 17 & $258 \pm 202$ & $819 \pm 307$ & $1,787 \pm 827$ & $17 \pm 33$ & $184 \pm 112$ & $5 \pm 10$ & $31 \pm 39$ & $6,806 \pm 5,845$ & $56 \pm 25$ & $3 \pm 3$ & $2 \pm 2$ & $2 \pm 3$ & 0 \\
\hline
\end{tabular}

a Abbreviations: F. graminearum $(F g), F$. culmorum $(F c), F$. avenaceum $(F a), F$. tricinctum $(F t), F$. poae $(F p), F$. sporotrichioides $(F s), F$. langsethiae $(F l)$, M. nivale/majus $(M) ; n=$ number of tested samples; $95 \%=95 \%$ of the samples are found in this interval. Detection limits: DON, NIV, and HT- $2>10 \mu \mathrm{kg} \mathrm{g}^{-1}$; ZEA $>2 \mu \mathrm{g} \mathrm{kg}^{-1} ; \mathrm{T}-2>5 \mu \mathrm{g} \mathrm{kg}-1$.

TABLE 6. Quantification of Fusarium and Microdochium nivale/majus biomass and the mycotoxins deoxynivalenol (DON), nivalenol (NIV), zearalenone (ZEA), HT-2, and T-2 in eight pooled historical wheat samples from the ASKOV location in 1957 to 2000 described by mean values ${ }^{\mathrm{a}}$

\begin{tabular}{|c|c|c|c|c|c|c|c|c|c|c|c|c|}
\hline \multirow[b]{2}{*}{ Year } & \multicolumn{7}{|c|}{ Amount of Fusarium DNA (pg fungal DNA/ $/ \mathrm{g}$ of plant DNA) } & \multicolumn{5}{|c|}{ Fusarium mycotoxins $\left(\mu \mathrm{g} \mathrm{kg}^{-1}\right)$} \\
\hline & $\mathrm{Fg}$ & $F c$ & $\mathrm{Fa}$ & $F t$ & $F p$ & $F l$ & $M$ & DON & NIV & ZEA & HT-2 & $\mathrm{T}-2$ \\
\hline $1957-1960$ & 0 & 122 & 0 & 0 & 43 & 0 & 198 & 66 & 12 & nd & nd & nd \\
\hline $1965-1968$ & 119 & 0 & 100 & 0 & 0 & 0 & 345 & 69 & 17 & nd & nd & nd \\
\hline $1981-1984$ & 0 & 171 & 18 & 0 & 76 & 0 & 378 & nd & nd & nd & nd & nd \\
\hline 1985-1989 & 0 & 199 & 300 & 0 & 80 & 0 & 620 & 62 & 26 & nd & nd & nd \\
\hline 1989-1992 & 0 & 33 & 16 & 0 & 100 & 0 & 151 & nd & 11 & nd & nd & nd \\
\hline
\end{tabular}

a Abbreviations: F. graminearum $(F g), F$. culmorum $(F c), F$. avenaceum $(F a), F$. tricinctum $(F t), F$. poae $(F p), F$ sporotrichioides $(F s), F$. langsethiae $(F)$, M. nivale/majus $(M)$; $\mathrm{nd}=$ not determined. Detection limits: DON, NIV, and HT- $>10 \mu \mathrm{g} \mathrm{kg}^{-1}$; ZEA $>2 \mu \mathrm{g} \mathrm{kg}^{-1} ; \mathrm{T}-2>5 \mu \mathrm{g} \mathrm{kg}^{-1}$.

TABLE 7. Quantification of Fusarium and Microdochium nivale/majus biomass and the mycotoxins deoxynivalenol (DON), nivalenol (NIV), zearalenone (ZEA), HT-2, and T-2 in eight pooled historical barley samples from the ASKOV location in 1957 to 2000 described by mean values ${ }^{\mathrm{a}}$

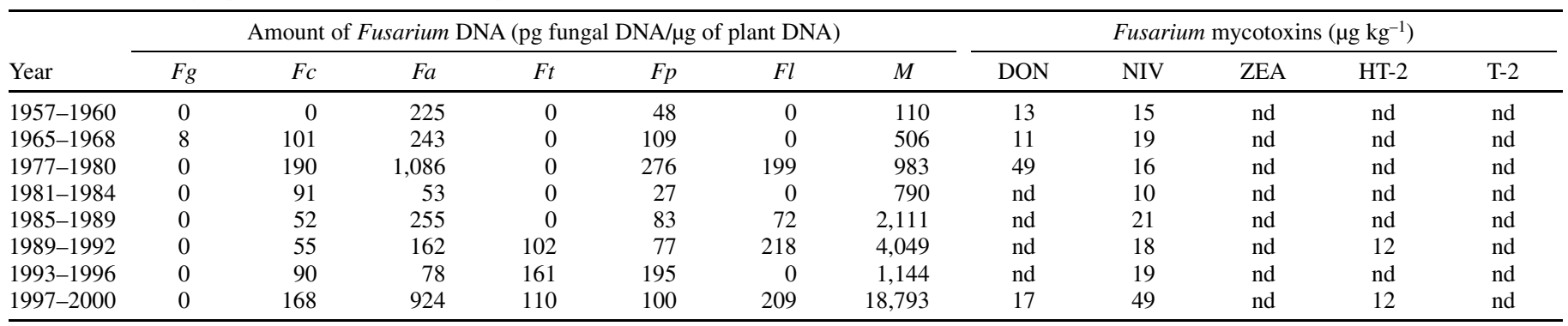

a Abbreviations: F. graminearum $(F g), F$. culmorum $(F c), F$. avenaceum $(F a), F$. tricinctum $(F t), F$. poae $(F p), F$. sporotrichioides $(F s), F$. langsethiae $(F)$, M. nivale/majus $(M) ; n=$ number of samples tested; nd = not determined. Detection limits: DON, NIV, and HT- $2>10 \mu \mathrm{kg}^{-1} ; \mathrm{ZEA}>2 \mu \mathrm{g} \mathrm{kg}-1$; $-2>5 \mu \mathrm{g} \mathrm{kg}{ }^{-1}$. 
both wheat and barley in 1965 to 1968 and then again in 1997 to 2000 in wheat. F. tricinctum was found exclusively on barley in 1989 to 2000. No F. sporotrichioides, F. equiseti, F. proliferatum, or $F$. verticilloides were found in these samples whereas $M$. nivale and M. majus were found in all years in both wheat and, especially, barley. The occurrence of mycotoxins in both barley and wheat showed a dominance of type B trichothecenes and very low amounts of the type A trichothecenes. NIV was found more abundantly than DON in barley, whereas DON was found more abundantly than NIV in wheat. No T-2 was found in either wheat or barley and HT-2 was only found in barley after 1989. ZEA was only found in a few samples of wheat in 1977 to 1980 and 1997 to 2000 .

Correlations between year, the species of the FHB complex, and mycotoxins by PCA analysis. Wheat samples $(n=219)$ from 2003 to 2007 were plotted as a biplot in Figure 1. This shows both the distribution of the samples in the two most descriptive dimensions of data and the variables spanning these two directions. On the x-axis, component 1 describes $29 \%$ of the variability and, on the y-axis, component 2 describes an additional $14 \%$ of the original variability. From the PCA, it is evident that levels of the mycotoxins DON, NIV, and ZEA are correlated with the biomass of $F$. graminearum and $F$. culmorum but also with $F$. avenaceum and $M$. nivale/majus in the direction of component 1 . The biomass of $F$. tricinctum, F. poae, and $F$. langsethiae spans component 2 and is correlated with the mycotoxin HT-2, whereas the biomass of $F$. sporotrichioides and the mycotoxin T-2 is not well described by the two first components. The samples are marked with the year of sampling, and there appears to be a pattern of separation between the 5 years, indicated by the concentration ellipsis which encompass $50 \%$ of data for a given year. The correlations in the direction of component 1 and 2 are mainly due to the year; 2003 and 2004 were years with much fusarium infection, whereas the years 2005 and 2007 were less conducive to infection and, therefore, influenced the correlation less. Finally, 2006 appears not to be conducive to infection, and this is also apparent in Table 2. Exploration of patterns with respect to $F$. sporotrichioides and T-2 was done by examination of higher, less-descriptive, components, which indicate that the presence of $F$. sporotrichioides is correlated with the presence of both $F$. poae and HT-2 toxins (data not shown), whereas T-2 finds no description in higher components due to extremely low levels of this mycotoxin in wheat (Table 2).

Barley samples $(n=59)$ from the 2005 to 2007 were plotted as a biplot in Figure 2 (component $1=24 \%$ and $2=18 \%$ ). From the PCA, it is evident that the mycotoxins DON and NIV correlate with the biomass of $F$. graminearum, $F$. culmorum, $F$. avenaceum, $F$. poae, and $M$. nivale/majus in the direction of component 1 . Levels of the mycotoxins HT-2 and T-2 correlate with the biomass of F. langsethiae and F. tricinctum and span component 2. Neither the mycotoxin ZEA nor pathogen $F$. sporotrichioides are described well by the two first components. The samples are, as above, marked with the year, and there is a pattern of separation between the 3 years. The correlations in the direction of component 1 are ascribed to the year 2007 whereas 2006 mainly influenced the correlations in the direction of component 2 and 2005 appeared to have been a less conducive year to Fusarium infections in barley, which is also observed in Table 3. Exploration of patterns with respect to ZEA and $F$. sporotrichioides can be done by examination of higher, less descriptive, components, which indicate that the presence of both ZEA and $F$. sporotrichioides are correlated with the presence of both T-2 and HT-2 (data not shown).

Triticale samples $(n=55)$ from 2005 to 2007 are plotted as a biplot in Figure 3 (component $1=26 \%$ and $2=17 \%$ ). From the PCA, it is evident that the mycotoxins DON and NIV correlate

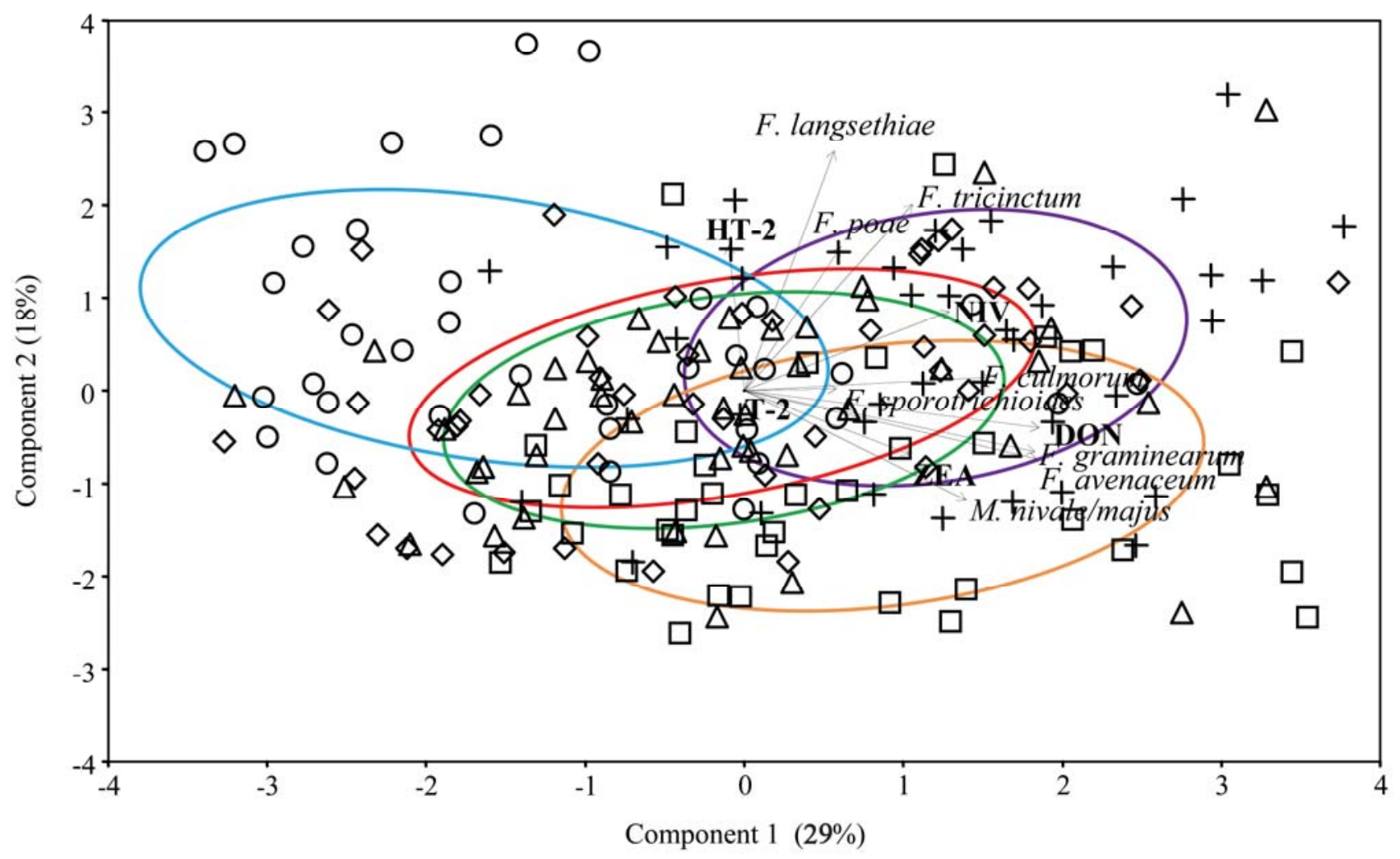

Fig. 1. Wheat biplot of the principal component analysis of levels of mycotoxins deoxynivalenol (DON), nivalenol (NIV), zearalenone (ZEA), HT-2, and T-2 and biomass of Fusarium graminearum, F. culmorum, F. avenaceum, F. tricinctum, F. poae, F. sporotrichioides, F. langsethiae, and Microdochium nivale/majus. Each ellipse encompasses 50\% of the data for a given year. Year: $2003(+), 2004(\square), 2005(\diamond), 2006(\bigcirc)$, and $2007(\triangle)$. 
with the biomass of $F$. graminearum, $F$. culmorum, $F$. avenaceum, and $M$. nivale/majus in the direction of component 1 . The biomass of $F$. langsethiae and $F$. tricinctum and ZEA span component 2 . The biomass of $F$. poae and $F$. sporotrichioides and the mycotoxins HT-2 and T-2 are not well described by the two first components. The samples are, as for barley, marked with the year, and there appears to be a pattern of separation between the 3 years. The correlations in the direction of component 1 and 2 are attributable to the years 2005 and 2007 whereas 2006 appears to have been a less conducive year to Fusarium infections in this crop. Exploration of patterns with respect to $F$. poae and $F$. sporotrichioides and the mycotoxins HT-2 and T-2 was performed by examination of higher, less descriptive, components, which indicated that the presence of $F$. poae correlated with the presence of $F$. avenaceum, whereas $F$. sporotrichioides, HT-2, and T-2 cannot be described in higher components (data not shown) due to low levels of these mycotoxins in triticale (Table 4).

\section{DISCUSSION}

This study is the first of its kind to give this detailed information, in terms of frequency and biomass for 11 Fusarium spp. causing FHB in five different small grain cereals over 1 to 5 years. The QPCR assays not only provide a measure for the fungal biomass but also reveal the true predominance of the individual species in the FHB complex. This information was then linked by PCA analysis to the occurrence of the relevant Fusarium-related mycotoxins. Although higher amounts of mycotoxins were seen in some years, they never exceeded the limits of Fusarium mycotoxins in unprocessed grain permitted by the European Union (EU). Major differences were observed between the FHB complex in the five different cereal species as well as substantial year-to-year variation, and analysis of historical barley and wheat samples indicated a shift in the FHB complex toward more F. graminearum. Correlations between the biomass of indi- vidual Fusarium spp. and the corresponding mycotoxins illustrated that, by monitoring the individual Fusarium spp., it is possible to predict the potential for mycotoxin contamination.

There is generally limited knowledge of the Fusarium spp. composition on the major cereals (wheat, barley, oat, triticale, and rye), let alone in Denmark. Prior knowledge of the frequency of Fusarium spp. in Danish cereals was based on three morphological studies of Fusarium spp. on barley. A study on barley from harvested plots in 1967 across Denmark found Fusarium spp. on $\approx 5 \%$ of the seed, with a dominance of $F$. avenaceum, $F$. poae, $F$ graminearum, M. nivale/majus, and F. culmorum (39). Another study of Fusarium spp. isolated from Danish malting barley found $F$. tricinctum and $F$. avenaceum as the dominant species followed by $F$. poae (1). A minor study of Danish cereals by Thrane (33) showed that $F$. avenaceum and $F$. culmorum were the most frequent species. It has been assumed, based on the study by Thrane (33) and the species composition in other northern European countries within the same climatic zone, that $F$. avenaceum and $F$. culmorum were the dominant Fusarium spp. in Danish cereals (5). The incidence data in the present study confirm the assumptions made by Bottalico and Perone (5) and further add that $M$. nivale and $M$. majus were the most frequent species across the years and crops. Furthermore, the conclusions of the three older morphological studies $(1,33,39)$ were also reflected in the 16 historical samples of wheat and barley analyzed in this study. Here, F. culmorum, F. avenaceum, and $M$. nivale/majus were found in samples from the period 1957 to 2000 but $F$. graminearum was absent in most years and only present in low amounts in wheat samples from the period 1965 to 1968 and again in samples from the period 1997 to 2000.

Because both frequency and biomass were measured, a more detailed picture of the FHB complex in wheat, barley, triticale, oat, and rye was obtained. F. graminearum was found to be the most abundant species in wheat, in terms of biomass, and this was consistent for all years. F. langsethiae, F. avenaceum, and F. poae

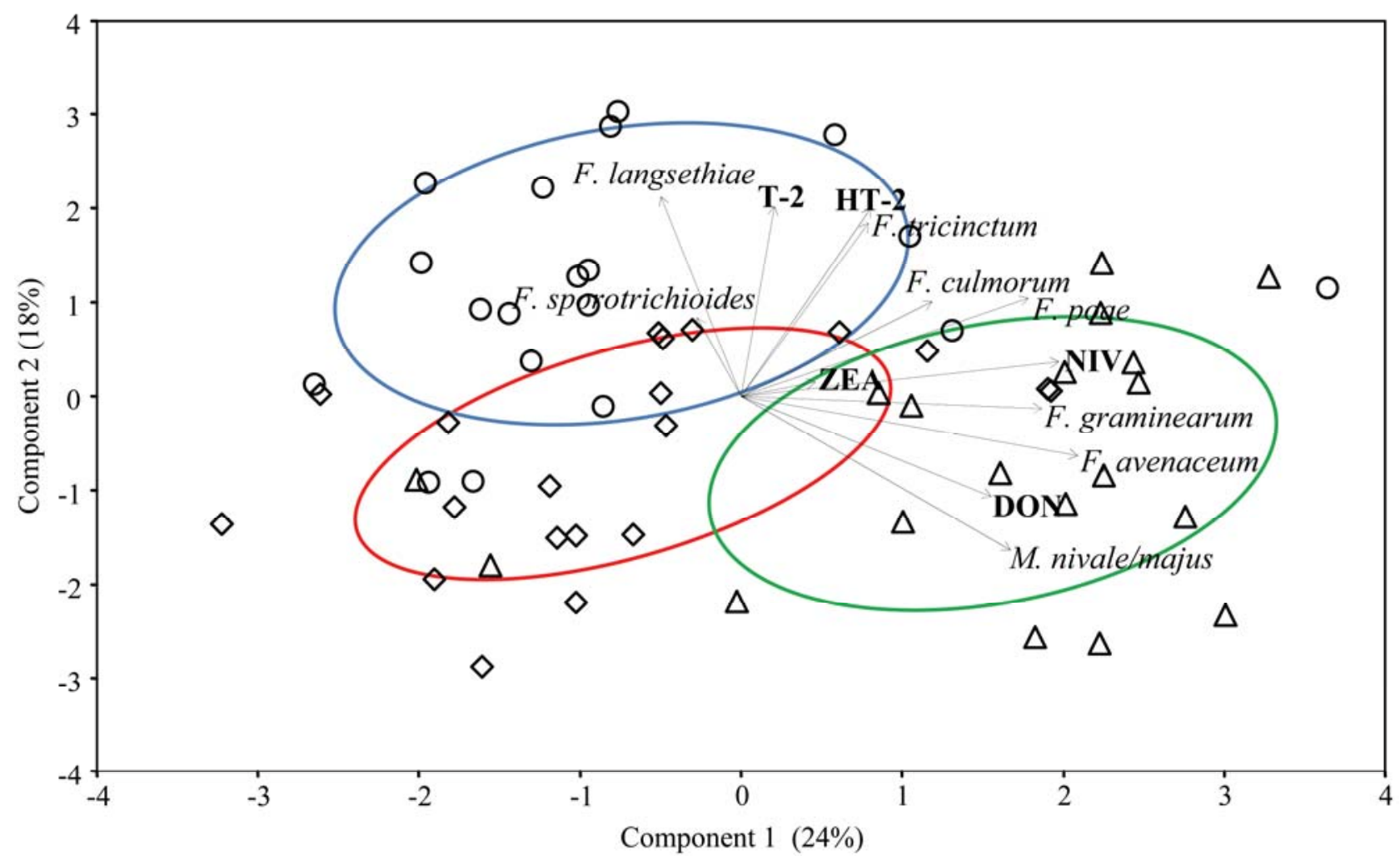

Fig. 2. Barley biplot of the principal component analysis of levels of mycotoxins deoxynivalenol (DON), nivalenol (NIV), zearalenone (ZEA), HT-2, and T-2 and biomass of Fusarium graminearum, F. culmorum, F. avenaceum, F. tricinctum, F. poae, F. sporotrichioides, F. langsethiae, and Microdochium nivale/majus. Each ellipse encompasses $50 \%$ of the data for a given year. Year: $2005(\diamond), 2006(O)$, and $2007(\triangle)$. 
were the predominant Fusarium spp. over the years in barley and oat. In contrast, in triticale, the predominant species was $F$. culmorum and, in rye, $F$. avenaceum. In the present study, $M$. nivale/majus was generally the most abundant in terms of biomass over years and cereal species, especially in 2007, where very high amounts of biomass were detected in all cereal species. $M$. nivale and $M$. majus are well-known pathogens of cereals included in the species complex of foot rot and FHB (5). At temperatures $<18^{\circ} \mathrm{C}$, conidia of $M$. nivale and $M$. majus are more competitive than species belonging to the Fusarium genus (7). In cooler areas of Europe, such as Denmark, this species might have an advantage over the other species in the FHB complex. These two species, which previously belonged to the Fusarium genus, have often caused confusion in predictions of DON content based on visual symptoms because their symptoms resemble those of $F$. graminearum and F. culmorum. Waalwijk et al. (37) showed that the nontoxigenic $M$. majus was almost completely absent from wheat ears where high levels of toxigenic Fusarium spp. were found. In the present study, there was a constant occurrence of $M$. nivale/majus with type B trichothecene-producing Fusarium spp.; further studies must be made to reveal whether it is $M$. nivale or M. majus that is the dominant species.

Although only a limited number of historical samples were available for this study, the results indicates that there has been a recent change in the FHB complex composition toward more $F$. graminearum in Denmark around year 2000, which has also been reported for several European countries $(16,17,27,32,37,42)$. The change has been proposed to be linked to an increase in minimum tillage and maize cropping $(3,10,23,31)$. Wheat samples originating from crop rotations with maize as the previous crop were not included in this study, because $<1 \%$ of the wheat area in Denmark has maize as the previous crop. However, a separate analysis of 21 samples from fields having maize as the previous crop showed very high and dominating levels of $F$. graminearum and very high amounts of DON compared with wheat samples from other cropping systems (data not shown). This clearly indicates that wheat grown in rotation with maize has a high risk for being contaminated with mycotoxins produced by $F$. graminearum, especially, which has also been shown by several studies $(8,10,27)$. Maize was introduced as a crop in Denmark in the beginning of the 1980s; maize area increased to 50,000 ha in 2000 and, since then, it has further increased to 150,000 ha in 2008 (representing $5.6 \%$ of the agricultural area). This is most likely to be responsible for promoting the shift toward $F$. graminearum. A general increase in the winter cereal area in Denmark as well as an increasing trend toward cropping using reduced tillage and stubble management could also have contributed to the changes, as also proposed by Champeil et al. (8). Another feasible explanation for the changes toward more $F$. graminearum may involve a gradual adaptation of the fungus to the cooler climate and, at the same time, changes in climate toward warmer and more humid summers could also have an effect in the increase of $F$. graminearum (41). Superior competitiveness of $F$. graminearum in wheat over other Fusarium spp. may provide yet another explanation for its increase in cooler regions of Europe (43).

In the present survey, 2003 and 2004 favored the development of $F$. graminearum and DON production. Rainfall and consequent high humidity are important for infection $(18,28)$. Although no specific analysis was carried out on local weather data from the individual fields and the occurrences of FHB, high precipitation during flowering was recorded in both of these seasons (www.dmi.dk). F. graminearum is described to have temperature optimum for both infection and growth of $\approx 28$ to $29^{\circ} \mathrm{C}$ (30). This is considerably higher than the Danish average temperature in June, which has varied between 13.5 and $16.0^{\circ} \mathrm{C}$ in the time period 2003 to 2007 (www.dmi.dk). In June and July 2007, the precipitation was twice the seasonal average; even so, it was dry during flowering, which limited the initial infection. In the 2007 season, $M$. nivale/majus and $F$. avenaceum dominated on the

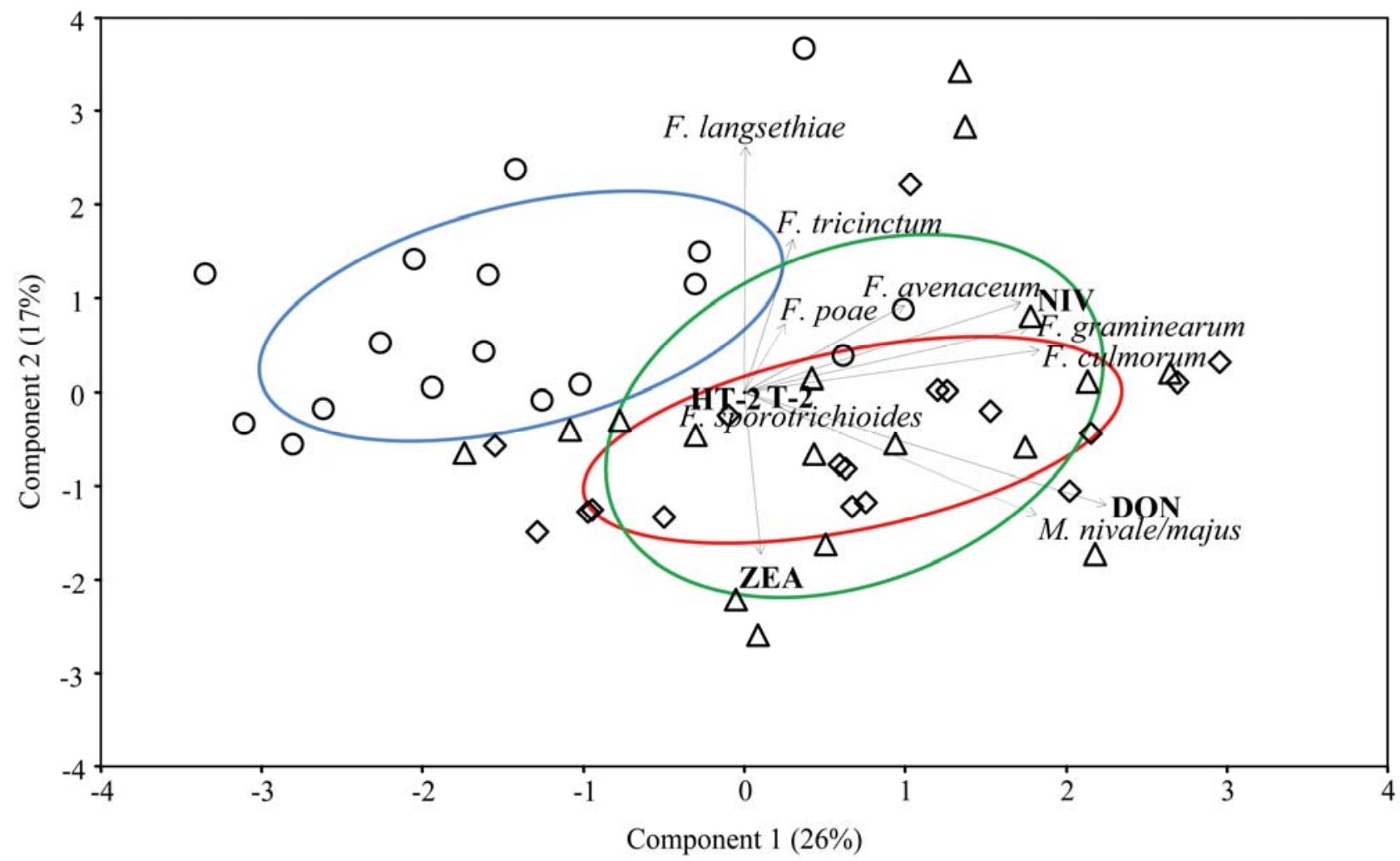

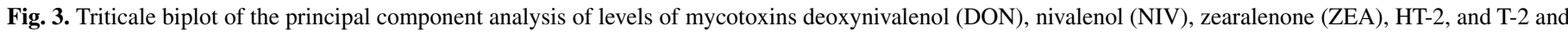

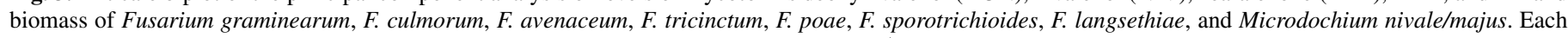
ellipse encompasses $50 \%$ of the data for a given year. Year: $2005(\diamond), 2006(\bigcirc)$, and $2007(\triangle)$. 
grain, and clear leaf symptoms of $M$. nivale/majus were also observed in that year, indicating that these weather conditions were very favorable for $M$. nivale/majus. This is in accordance with previous studies, which showed that $F$. avenaceum and $M$. nivale/majus are the greatest producers of conidia under moist and cool conditions (30). The historical samples of barley showed an increase in the amount of $M$. nivale/majus in barley during the time span 1957 to 2000 , as opposed to wheat in the same time period; however, the possible explanation for this change is not clear.

$F$. langsethiae and $F$. poae were abundant, especially in barley and oat. F. langsethiae was found to be present at high levels in barley, not only in recent years but also in the samples from 1977 to 1980 , demonstrating that this species was present before it was first described (36). An increasing occurrence of $F$. poae has been recorded in recent years $(2,43)$. $F$. poae is generally described as less pathogenic $(6,40)$ as well as a secondary invader, colonizing the weakened ears sometimes already infected by other, more aggressive Fusarium spp. such as $F$. graminearum (2). Even though $F$. poae has been described to be associated with warm and dry weather (42), it has been found commonly in Nordic regions, where it is clearly associated with content of NIV (44).

A multivariate statistical analysis (PCA) was employed to investigate correlations between the individual 10 Fusarium spp. and $M$. nivale/majus as well as the associated mycotoxins. The PCA analysis generally showed positive correlations between the biomass of individual Fusarium spp. and their corresponding mycotoxins, verifying the ability of the different species to produce specific mycotoxins under field conditions. In wheat, two defined groups are seen describing the Fusarium spp., producing either type A or type B trichothecenes. For type B trichothecenes, levels of DON and ZEA were found to correlate with $F$. graminearum and $F$. culmorum but also to other species such as $F$. avenaceum and $M$. nivale/majus. Although the latter do not produce DON and NIV, this correlation might indicate that these species are favored by the same environmental conditions. It is possible that, due to competition between species, these species are stimulating DON production in $F$. graminearum and $F$. culmorum. In the group of type A trichothecenes, HT-2 was found to correlate with $F$. langsethiae, $F$. tricinctum, and $F$. poae. $F$. langsethiae is a known producer of HT-2 but the PCA analysis indicates that $F$. poae might also be responsible for some HT-2 because a few isolates of $F$. poae have been shown to produce T-2 and HT-2 (35). F. tricinctum is considered to be nontrichothecene producer (34) but may be stimulated by the same growth conditions as $F$. langsethiae and $F$. poae. The type B trichothecene NIV is located on the plot between the two groups described above, indicating a correlation with both $F$. graminearum and $F$. culmorum in the first group as well as $F$. poae in the second group. It was seen that levels of the two trichothecene groups did not correlate, and the correlations were greatly affected by the different years.

In barley, as in wheat, two groups separating type A and type B trichothecenes were seen; however, ZEA was not detected and, therefore, not described, and $F$. poae correlated with the type B trichothecene group. The reasons for the low levels of ZEA appear unclear. A clear separation of the years was seen: 2007 showed a preference for type B, 2006 defined type A, and 2005 did not contribute to the correlations. In triticale, the type A trichothecenes were not detected but DON correlated with $F$. graminearum and $F$. culmorum correlated with NIV. Again, $M$. nivale/majus levels were found to correlate with $F$. graminearum and $F$. langsethiae was seen to correlate with $F$. tricinctum, indicating that these species are stimulated by the same environmental conditions or agricultural practices.

The existence of a complex of Fusarium spp. within single field samples has previously been shown $(2,4,15)$. In the present study, up to seven different Fusarium spp., along with $M$. nivale/ majus, were often found in single grain samples, confirming the existence of a diverse Fusarium species complex. Audenaert et al. (2) recorded up to nine Fusarium spp. in addition to M. nivale in one sample and found clear associations between $F$. poae and $F$. avenaceum as well as between $F$. graminearum and $M$. nivale/ majus. The former finding was not confirmed in our data, whereas the latter finding is in accordance with the Danish data from wheat, barley, and triticale, where the biomass of $M$. nivale/majus seems to be correlated with the biomass of F. graminearum.

Interesting observations concerning the ratio between DON and NIV in wheat and barley are apparent in Tables 2 and 3. In wheat, the DON/NIV ratio is $\approx 20: 1$ whereas, in barley, the DON/NIV ratio is close to $1: 1$. These differences might be related either to the ratio between the NIV producers $F$. graminearum or $F$. culmorum and $F$. poae or the fact that NIV chemotypes of $F$. graminearum and F. culmorum are associated with barley. However, Tables 2 and 3 clearly show differences in the ratio between the DON-producing species $F$. graminearum and $F$. culmorum and NIV-producing $F$. poae. In wheat, the $F$. graminearum or $F$. culmorum/F. poae ratio varies from 10:1 to $100: 1$, whereas, in barley, the ratio varies from $2: 1$ to $1: 3$. Bottalico and Perone (5) reported that NIV found in cereals in Sweden and northern Europe most likely is produced by $F$. poae.

In the present study, it was possible to study the presence of 11 individual fungal species in 396 grain samples, a task which would have been extremely laborious and difficult to carry out using traditional culturing methods, assuming that it would have been possible to extract viable spores from these samples. The same DNA-extraction method was used for all cereal species and the amplification efficiencies were comparable in the different cereal backgrounds. The fungal biomass was calculated as the amount of fungal DNA normalized with the amount of plant DNA for each sample in order to compensate for variations in DNA yield and presence of PCR inhibitors. However, due to differences in genome sizes, comparison of biomass data from different cereal species should be avoided. Validation experiments using mixtures of DNA from closely related species showed that PCR amplification of low amounts of target DNA from one species may be affected by the presence of high amount of DNA from a closely related species, and this may lead to some overestimation of the species present in low amounts. However, the QPCR methods will allow detection and quantification of species present in very low amounts, in contrast to conventional methods, where the presence of especially slow-growing or dead species will be underestimated.

FHB is not considered a serious threat to Danish grain production because crop rotations and tillage methods are most commonly nonconducive to severe attack by FHB. Nevertheless, this study has shown that the Fusarium spp. capable of producing mycotoxins are common on Danish grain, and can give rise to widespread attack in seasons where climate stimulates infection and growth of Fusarium spp. The mycotoxin monitoring project by Knowledge Centre for Agriculture, Crop Production, shows that from common agricultural practices in Denmark no samples collected during 2005 to 2010 exceed the permitted limits for DON given by the EU (G. C. Nielsen, unpublished data). In 2003 and 2004, where the grown cultivars were more susceptible and weather more favorable for Fusarium, several wheat samples exceeded the permitted limits for DON. The wheat cultivars grown in Denmark generally exhibit low to medium resistance to FHB (20) and that, in general, farmers do not apply fungicides to control FHB, because the risk is considered low and trials have shown low yield responses for control. Because the fungal species involved in FHB differ in pathogenicity, mycotoxin production, and response to cropping practice and fungicides, the correct identification and quantification is considered important for further development of risk assessments and control strategies. 


\section{ACKNOWLEDGMENTS}

This work is funded by the Directorate for Food, Fisheries and Agri Business grant no. 3304 FVFP 060678 "Fusarium disease resistancetoxins and feed quality" and Plant Biotech Denmark. We thank M. A. Rasmussen (University of Copenhagen) for statistical advice and H. J. L. Jørgensen (University of Copenhagen) for critically reading the manuscript.

\section{LITERATURE CITED}

1. Andersen, B., Thrane, U., Svendsen, A., and Rasmussen, I. A. 1996. Associated mycobiota on malt barley. Can. J. Bot. 74:854-858.

2. Audenaert, K., Van Broeck, R., Bekaert, B., De Witte F., Heremans, B., Messens, K., Höfte, M., and Haesaert, G. 2009. Fusarium head blight (FHB) in Flanders: population diversity, inter-species associations and DON contamination in commercial winter wheat varieties. Eur. J. Plant Pathol. 125:445-458.

3. Bateman, G. L., Gutteridge, R. J., Gherbawy, Y., Thomsett, M. A., and Nicholson, P. 2007. Infection of stem bases and grains of winter wheat by Fusarium culmorum and $F$. graminearum and effects of tillage methods and maize-stalk residues. Plant Pathol. 56:604-615.

4. Bottilico, A. 1998. Fusarium diseases of cereals: Species complex and related mycotoxin profiles. Eur. J. Plant Pathol. 80:85-103.

5. Bottalico, A., and Perrone, G. 2002. Toxigeneic Fusarium species and mycotoxins associated with head blight in small-grain cereals in Europe. Eur. J. Plant Pathol. 108:611-624.

6. Brennan, J. M., Fagan, B., van Maanen, A., Cooke, B. M., and Doohan, F. M. 2003. Studies on in vitro growth and pathogenicity of European Fusarium fungi. Eur. J. Plant Pathol. 109:577-587.

7. Champeil, A., Dore, T., and Fourbet, J. F. 2004. Fusarium head blight: epidemiological origin of the effects of cultural practices on head blight attacks and the production of mycotoxins by Fusarium in wheat grains. Plant Sci. 166:1389-1415.

8. Champeil, A., Fourbet, J. F., and Rossignol, L. 2004. Influence of cropping system on Fusarium head blight and mycotoxin levels in winter wheat. Crop Prot. 23:531-537.

9. Christensen, B. T., Petersen, J., and Trentemøller, U. M. 2006. The Askov Long-Term Experiments on Animal Manure and Mineral Fertilizers: The Lermarken Site 1894-2004. DIAS Report. Plant Production no. 121.

10. Dill-Macky, R., and Jones, R. K. 2000. The effect of previous crop residues and tillage in Fusarium head blight of wheat. Plant Dis. 84:71-76.

11. D’Mello, J. P. F., Placinta, C. M., and Macdonald, A. M. C. 1999. Fusarium mycotoxins: a review of global implications for animal health, welfare and productivity. Anim. Feed Sci. Technol. 80:183-205.

12. Glynn, N. C., and Edwards S. G. 2010. Evaluation of PCR assays for quantifying seed-borine infection by Fusarium and Microdochium seedling blight pathogens. J. Appl. Microbiol. 108:81-87.

13. Glynn, N. C., Hare, M. C., Parry, D. W., and Edwards, S. G. 2005. Phylogenetic analysis of EF-1 alfa gene sequences from isolates of Microdochium nivale leads to elevation of varieties majus and nivale to species status. Mycol. Res. 109:872-880.

14. Hammer, Ø., Harper, D. A. T., and Ryan, P. D. 2001. PAST: Paleontological Statistics Software Package for Education and Data Analysis. Palaeontologia Electronica 4. http://palaeo-electonica.org/2001_1/past/ issue1_01.htm

15. Ioos, R., Belhajd, A., and Menez, M. 2004. Occurrence and distribution of Microdochium nivale and Fusarium species isolated from barley, durum and soft wheat grains in France from 2000 to 2002. Mycopathologia 158:351-362.

16. Isebaert, S., De Saeger, S., Devreese, R., Verhoeven, R., Maene, P., Heremans, B., and Haesaert, G. 2009. Mycotoxin-producing Fusarium species occurring in winter wheat in Belgium (Flanders) during 20022005. J. Phytopathol. 157:108-116.

17. Jennings, P., Coates, M. E., Walsh, K., Turner, J. A., and Nicholson P. 2004. Determination of deoxynivalenol- and nivalenol-producing chemotypes of Fusarium graminearum isolated from wheat crops in England and Wales. Plant Pathol. 53:643-652.

18. Jennings, P., and Turner, J. A. 1996. Towards the prediction of Fusarium ear blight epidemics in the UK-the role of humidity in disease development. Pages 233-238 in: Proc. Brighton Crop Prot. Conf. BCPC Publications, Farnham, UK.

19. Johnson, R. A., and Wichern, D. W. 1982. Applied Multivariate Statistical Analysis. Prentice-Hall, Inc., Englewood Cliffs, NJ.

20. Jørgensen L. N., Nielsen L. K., and Spliid, N. H. 2010. Sorters modtagelighed over for Fusarium og DTR. In: Pesticidafprøvning 2009. DJF rapport markbrug 146. Det Jordbrugsvidenskabelige fakultet, Aarhus Universitet.

21. Kosiak, B., Torp, M., Skjerve, E., and Thrane, U. 2007. The prevalence and distribution of Fusarium species in Norwegian cereals: a survey. Acta Agric. Scand. Sect. B Soil Plant Sci. 53:168-176.
22. Krska, R., Baumgartner, S., and Josephs, R. 2001. The state-of-the-art in the analysis of type-A and type-B trichothecene mycotoxins in cereals. Fresenius Z. Anal. Chem. 371:285-299.

23. Logrieco, A., Mulè, G., Moretti, A, and Bottalico, A. 2002. Toxigenic Fusarium species and mycotoxins associated with maize ear rot in Europe. Eur. J. Plant Pathol. 108:597-609.

24. Moss, M. O., and Thrane, H. 2004. Fusarium taxonomy with relation to trichothecene formation. Toxicol. Lett. 153:23-28.

25. Nicolaisen, M., Suproniene, S., Nielsen, L. K., Lazzaro, I., Spliid, N. H., and Justesen, A. F. 2009. Real time PCR for quantification of eleven individual Fusarium species in cereals. J. Microbiol. Methods 76:234-240.

26. Niessen, L. 2007. PCR-based diagnosis and quantification of mycotoxin producing fungi. Int. J. Food Microbiol. 119:38-46.

27. Parry, D. W., Jenkinson, P., and McLeod, L. 1995. Fusarium ear blight (scab) in small grain cereals-a review. Plant Pathol. 44:207-238.

28. Paul, P. A., Lipps, P. E., De Wolf, E., Shaner, G., Buechley, G., Adhikari, T., Ali, S., Stein, J., Osborne, L., and Madden, L. V. 2007. A distributed lag analysis of the relationship between Gibberella zeae inoculum density on wheat spikes and weather variables. Phytopathology 97:1608-1624.

29. Pettitt, T. R., Parry D. W., and Polley, R. W. 1993. Improved estimation of the incidence of Microdochium nivale in winter wheat in England and Wales, during 1992, by use of benomyl agar. Mycol. Res. 97:1172-1174.

30. Rossi, V., Ravanetti A., Pattori, E., and Giosue, S. 2001. Influence of temperatures and humidity on the infection of wheat spikes by some fungi causing Fusarium head blight. J. Plant Pathol. 84:189-198.

31. Schaafsma, A. W., Tamburic-Ilincic, L., and Hooker, D. C. 2005. Effect of previous crop, tillage, field size, adjacent crop and sampling direction on airborne propagules of Gibberella zeae/Fusarium graminearum, Fusarium head blight severity, and deoxynivalenol accumulation in winter wheat. Can. J. Plant Pathol. 27:217-224.

32. Stepien, L., Popiel, D., Koczyk, G., and Chelkowski, J. 2008. Wheatinfecting Fusarium species in Poland-their chemotypes and frequencies revealed by PCR assay. J. Appl. Genet. 49:433-441.

33. Thrane, U. 2000. Mycotoxin producing Fusarium species occurring in Danish cereals. In: 17th Danish Plant Protection Conference II. DJFrapport 24:165-169.

34. Thrane, U. 2001. Developments in the taxonomy of Fusarium species based on secondary metabolites. Pages $29-49$ in: Fusarium. B. A. Summerell, J. F. Leslie, D. Backhouse, W. L. Bryden, and L. W. Burgess, eds. Paul E. Nelson Memorial Symposium. American Phytopathological Society, St. Paul, MN.

35. Thrane, U., Adler A., Clasen, P.-E., Galvano, F., Langseth, W., Lew, H., Logrieco, A. Nielsen, K. F., and Ritieni, A. 2004. Diversity in metabolite production by Fusarium langsethiae, Fusarium poae, and Fusarium sporotrichioides. Int. J. Food Microbiol. 95:257-266.

36. Torp, M., and Langseth, W. 1999. Production of T-2 toxin by a Fusarium resembling Fusarium poae. Mycopathologia 147:89-96.

37. Waalwijk, C., Kastelein P., de Vries, I., Kerényi, Z., van der Lee, T., Hesselink, T., Köhl J., and Kema, G. 2003. Major changes in Fusarium spp. in wheat in the Netherlands. Eur. J. Plant Pathol. 109:743-754.

38. Waalwijk, C., van der Heide, R., de Vries, I., van der Lee, T., Schoen C., Costrel-de Corainville, G., Häuser-Hahn, I., Kastelein P., Lonnet, P., Demarquet, T., and Kema G. 2004. Quantitative detection of Fusarium species in wheat using TaqMan. Eur. J. Plant Pathol. 110:481-494.

39. Welling, B. 1970. Undersøgelse af kornkvaliteten i praksis på grundlag af bygprøver indsamlet $\mathrm{i}$ foråret 1967. Pages 227-233 in: Kornkvalitetsudvalget under Akademiet for de tekniske Videnskaber. Rapport om udvalgets virksomhed. København, Denmark.

40. Xu, X.-M., Monger, W., Ritieni, A., and Nicholson, P. 2007. Effect of temperature and duration of wetness during initial infection periods on disease development, fungal biomass and mycotoxin concentrations on wheat inoculated with single, or combinations of, Fusarium species. Plant Pathol. 56:943-956.

41. Xu, X.-M, and Nicholson, P. 2009. Community ecology of fungal pathogens causing wheat head blight. Annu. Rev. Phytopathol. 47:83-103.

42. Xu, X.-M., Nicholson, P., Thomsett, M. A., Simpson, D., Cooke, B. M., Doohan, F. M., Brennan, J., Monoghan, S., Moretti, A., Mule, G., Hornok, L., Beki, E., Tatell, J., Ritieni, A., and Edwards, S. G. 2008. Relationship between the fungal complex causing Fusarium head blight of wheat and environmental conditions. Phytopathology 98:69-78.

43. Xu, X.-M., Parry, D. W., Nicholson, P., Thomsett, M. A., Simpson, D., Edwards, S. G., Cooke, B. M., Doohan, F. M., Brennan, J. M., Moretti, A., Tocco, G., Mule, G., Hornok, L., Giczey, G., and Tatnell, J. 2005. Predominance and association of pathogenic fungi causing Fusarium ear blight in wheat in four European countries. Eur. J. Plant Pathol. 112:143154.

44. Yli-Mattila, T., Paavanen-Huhtala, S., Parikka P., Konstantinova, P., and Gagkaeva, T. Y. 2004. Molecular and morphological diversity of $\mathrm{Fu}$ sarium species in Finland and northwestern Russia. Eur. J. Plant Pathol. 110:573-585. 